\title{
Combining remote sensing-simulation modeling and genetic algorithm optimization to explore water management options in irrigated agriculture
}

\author{
Amor V.M. Ines ${ }^{a, *}$, Kiyoshi Honda ${ }^{b, 1}$, Ashim Das Gupta ${ }^{c, 2}$, \\ Peter Droogers ${ }^{d, 3}$, Roberto S. Clemente ${ }^{c, 2}$ \\ ${ }^{a}$ Department of Biological and Agricultural Engineering, Texas A\&M University, 2117 TAMU, 201 Scoates Hall, \\ College Station, TX 77843-2117, USA \\ ${ }^{\mathrm{b}}$ Remote Sensing and Geographic Information Systems, School of Engineering and Technology, Asian Institute of Technology, \\ P.O. Box 4, Klong Luang 12120, Pathumthani, Thailand \\ ${ }^{\mathrm{C}}$ Water Engineering and Management, School of Engineering and Technology, Asian Institute of Technology, \\ P.O. Box 4, Klong Luang 12120, Pathumthani, Thailand \\ ${ }^{\mathrm{d}}$ FutureWater, Generaal Foulkesweg 28, 6703 BS Wageningen, The Netherlands
}

\section{A R T I C L E I N F O}

Article history:

Accepted 23 December 2005

Published on line 7 February 2006

Keywords:

Water management

Remote sensing

Simulation

Genetic algorithms

Data assimilation

Evapotranspiration

\begin{abstract}
A B S T R A C T
We present an innovative approach to explore water management options in irrigated agriculture considering the constraints of water availability and the heterogeneity of irrigation system properties. The method is two-folds: (i) system characterization using a stochastic data assimilation procedure where the irrigation system properties and operational management practices are estimated using remote sensing (RS) data; and (ii) water management optimization where we explored water management options under various levels of water availability. We set up a soil-water-atmosphere-plant model (SWAP) in a deterministic-stochastic mode for regional modeling. The distributed data, e.g. sowing dates, irrigation practices, soil properties, depth to groundwater and water quality, required as inputs for the regional modeling were estimated by minimizing the residuals between the distributions of field-scale evapotranspiration (ET) simulated by the regional application of SWAP, and by surface energy balance algorithm for land (SEBAL) using two Landsat7 ETM+ images. The derived distributed data were used as inputs in exploring water management options. Genetic algorithm was used in data assimilation and water management optimizations. The case study was conducted in Bata minor (lateral canal), Kaithal, Haryana, India during 2000-2001 rabi (dry) season. Our results showed that under limited water condition, regional wheat yield could improve further if water and crop management practices are considered simultaneously and not independently. Adjusting sowing dates and their distribution in the irrigated area could improve the regional yield, which also complements the practice of deficit irrigation when water availability is largely a constraint. This result was also found in agreement with the
\end{abstract}

\footnotetext{
* Corresponding author. Tel.: +1 979458 4651; fax: +1 9798623442.

E-mail addresses: avmines@tamu.edu (Amor V.M. Ines), honda@ait.ac.th (K. Honda), adg@ait.ac.th (A. Das Gupta), p.droogers@futurewater.nl (P. Droogers), clemente@ait.ac.th (R.S. Clemente).

1 Fax: +66 25245597.

2 Fax: +66 25246425 .

3 Tel.: +31317460050.

0378-3774/\$ - see front matter (C) 2006 Elsevier B.V. All rights reserved.

doi:10.1016/j.agwat.2005.12.006
} 
scenario that water is non-limited with the exception that the farmers have more degrees of freedom in their agricultural activities. An improvement of the regional yield to $8.5 \%$ is expected under the current scenario.

(C) 2006 Elsevier B.V. All rights reserved.

\section{Introduction}

Water plays a vital role in meeting the demand for food of the growing population. Irrigated agriculture, in fact, is considered as the major user of water in the world (Seckler et al., 1999). Recent studies suggest that the trend in the use of water is increasing significantly leading to some conclusions that water scarcity problem could be inevitable in the near future. Water scarcity would tighten more the competition of water causing more pressure into its utilization (Seckler et al., 1998). Under this circumstance a paradigm shift appears to be necessary, from a demand driven water management into a more supply driven one.

To realize this, a better understanding of the processes affecting the use of water in agriculture is necessary. Crop level analysis is important in this case, and upscaling the procedure to the system level is equally important to account for the impacts of system heterogeneities (Ines et al., 2002). Seckler (1996), Molden (1997), Ines et al. (2002), among others, proposed water-saving concepts in irrigated agriculture, where water productivity is proposed as a more practical measure for an effective water use in agriculture. Compared to the conventional notion of efficiencies (Bos and Nugteren, 1990; Bos, 1997) water productivity is considered as a more effective measure in evaluating the performance of an irrigation system. Efficiency indicators describe only the ratio of water flows (i.e. going out versus coming in) and deal with losses that can be partially recovered back into the system (in case of water re-use). Water productivity relates to crop outputs per unit water input or unit water output and when considering productivity per unit evapotranspiration (ET) there are no more losses recoverable back into the system. Applying these concepts in the field, however, requires rigorous experiments and data collection, opening opportunities to develop methods and techniques to explore their potentials in managing irrigated agriculture under limited water condition. Recent studies used remote sensing (RS), geographic information system (GIS) and simulation models to explore these concepts by assessing performance indicators and water balances in an irrigation system (e.g. Droogers and Kite, 1999; Droogers et al., 2000; Droogers and Bastiaanssen, 2002; Bastiaanssen et al., 2004). They are, however, more diagnostic in nature because only the performance indicators were evaluated and not the management strategies that could possibly improve the performance of the irrigation system. A more proactive approach appears to be necessary in this regard.

In exploring ways to improve the use of water in irrigated agriculture, it is always important to consider the issue of optimal water use considering the limited water resource and the limitations of the irrigation system per se, e.g. soil/water quality, heterogeneity in soils, etc. Usually, irrigation planning problems are based on area allocation approach wherein cultivated areas are allocated to crops to optimize an objective (Lakshminarayana and Rajagopalan, 1977; Jesus et al., 1987; Paudyal and Gupta, 1990; Raman et al., 1992). Under a situation when cropping pattern already exists, addressing the water allocation problem seems to be less explored. A proactive approach should be able to assist water managers to plan the distribution of water or sowing dates or the combination of both in the irrigated area considering the limitations of water supply and the system to maximize an objective. Generally, this type of problem is highly combinatorial in nature and sometimes the decision variables are implicit functions of the objective function requiring powerful search and optimization procedures (e.g. genetic algorithms) and system tools in the implementation (Mostesinos et al., 2001). This is compounded by the issue of heterogeneity in the irrigation system. Along this line, stochastic modeling (e.g. Hopmans, 1988; Hopmans and Stricker, 1989) could be extremely useful to explore water saving at the system level. It can be easily applied to describe the extent of the population (fields) that lowly utilizes the water resources, which should be ascribed to a water saving program.

This paper aims to present an innovative approach to explore water management options in irrigated agriculture using a combined RS-simulation modeling and genetic algorithm optimization. The method is two-folds: (i) system characterization using a stochastic data assimilation procedure where the irrigation system properties and operational management practices are estimated using RS data; and (ii) water management optimization where we explored water management options under various levels of water availability. We applied the method to an irrigation system during a wheat cropping season in Northwest India.

\section{Methodology}

\subsection{Description of the study area}

The case study was conducted in Bata minor at Kaithal, Haryana, India during the 2000-2001 rabi (dry) season (November-April). The minor (lateral canal) is about $19 \mathrm{~km}$ long offtaking from Sirsa Branch of the Bhakra Irrigation System (at $27.75^{\circ} \mathrm{N}, 76.38^{\circ} \mathrm{E}$ ). The command area is about 3669 ha and a design discharge of $0.65 \mathrm{~m}^{3} \mathrm{~s}^{-1}$. Climate in the study area is characterized as semi-arid with a normal annual rainfall of 500-600 $\mathrm{mm}$. Three dominant seasons are experienced in a year; summer from March to June, the rainy season, which starts from mid June to the end of September and winter from November to February. Cropping pattern varies from rice during the kharif (wet) season and wheat during the rabi (dry) season with some patches of sugarcane, mustard, cotton, millet and fodder crop. 
The distribution of water is based on the warabandi principle, which is a supply driven fixed-time rotational water delivery system (Berkoff and Huppert, 1987). Under this water delivery system, water distribution is implemented by rostering where the minors (laterals) along the main distributary canal (e.g. Sirsa Branch) are classified into different groups, e.g. A, B, C, etc., wherein each group will receive water on a rotational basis and at a fixed time allocation. When water is allowed to flow in the minor, the field canal (watercourse) outlets are all open along the minor from head to tail reach, receiving a continuous flow of water. Ideally, each farm holding in the command area of a watercourse gets the full supply in the watercourse for a specified period of time, proportional to its size (Berkoff and Huppert, 1987). Water is usually allowed to flow in the minor for two weeks depending on the available supply during the growing season. The rotation among the group of minors is also expected in a period of two weeks (Tyagi et al., 2005).

The problems of water shortage and salinity are prevalent in the study area impacting significantly to the levels of crop production (Boumans et al., 1988; Singh and Singh, 1997; Sakthivadivel et al., 1999). Water availability problem seems to be distributed among the system constituents with better opportunities for the head reach farmers. The farmers also use groundwater to supplement the available surface water during the growing season. Groundwater quality, however, varies in the command area with better qualities in the upstream than the downstream region. Evaluating these problems at the system level requires an innovative approach that would enable us to account for the spatial and temporal extents of the problems during the cropping season. Remote sensing combined with stochastic modeling and optimization procedures would be extremely useful in evaluating such problems at the system level. Fig. 1 shows the location of the study area in the Bhakra, Irrigation System.

\subsection{Modeling framework}

Fig. 2a shows the general framework of the study where there are two main procedures done: (i) system characterization; and (ii) water management optimization. Our regional modeling domain was represented by the regional application of a soil-water-atmosphere-plant model (SWAP; Van Dam et al., 1997), which requires distributed data, e.g. sowing dates, irrigation dates and frequencies, soil hydraulic properties, depth to groundwater, etc. as inputs for simulations and were derived from remote sensing data using a stochastic data assimilation scheme (Fig. 2b). In deriving these distributed input data, the distributions of ET calculated from surface energy algorithm for land (SEBAL; Bastiaanssen et al., 1998) were matched with the distributed ET simulated by the regional application of SWAP using genetic algorithm (GA). The derived distributed data are then used as inputs to the regional application of SWAP to solve our water management optimization model with the aim of exploring the best management options under given water management scenarios. Genetic algorithm was used both for data assimilation and optimization procedures. Details of the methods are discussed below.

\subsubsection{Setting up SWAP for regional modeling}

The heterogeneity of the system is accounted for by applying SWAP in a deterministic-stochastic mode (e.g. Hopmans, 1988; Hopmans and Stricker, 1989). We assumed that the probability density functions (pdfs) of selected stochastic variables, e.g. sowing dates, irrigation application criterion, soil hydraulic properties, water quality and depth to groundwater are known. Knowing the pdf, a value of a random variable can be derived from the distribution function. We assumed the pdfs to be normal because we did not have data on the distributions of these variables during the conduct of the study. We used a parametric

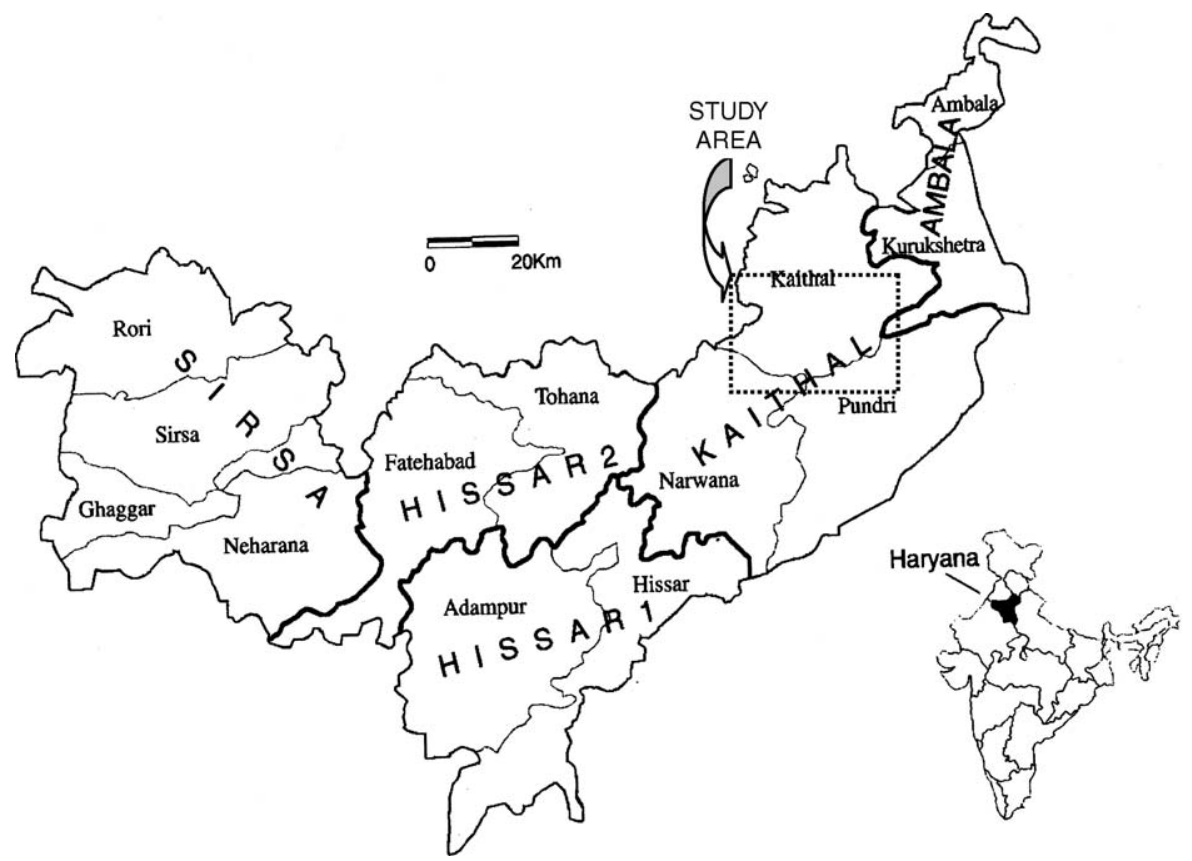

Fig. 1 - Location of the study area in the Bhakra Irrigation, System, Haryana, India (Sakthivadivel et al., 1999). 


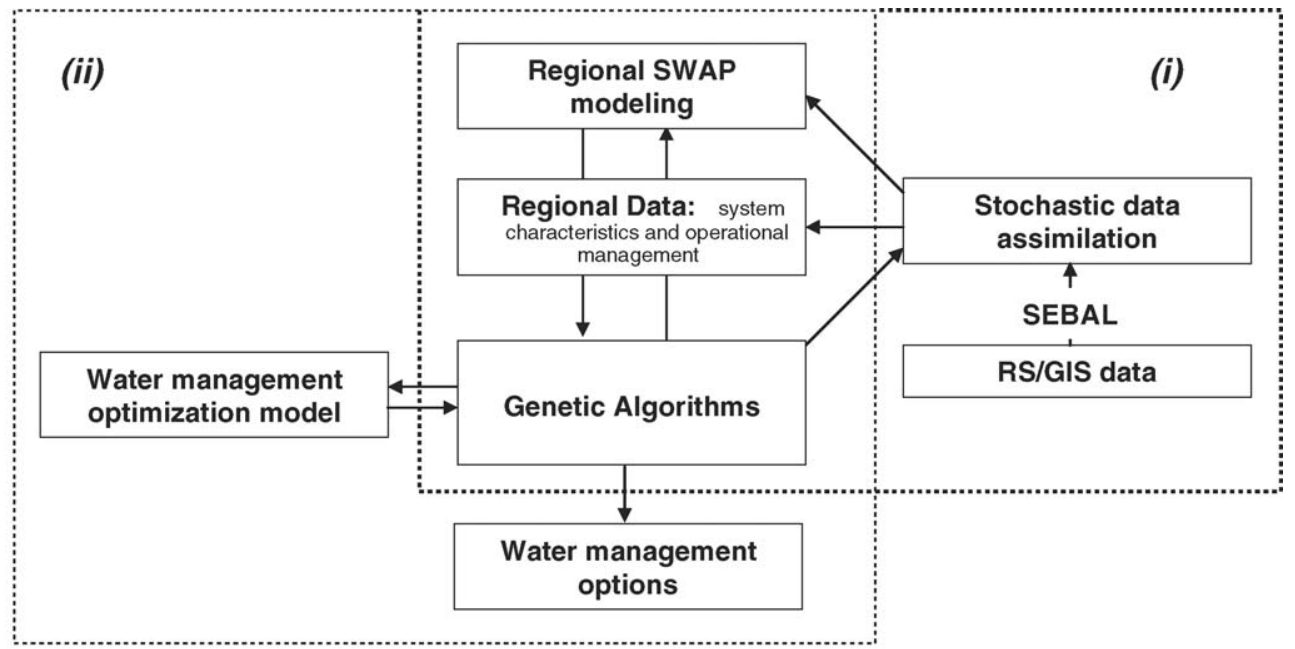

(a)
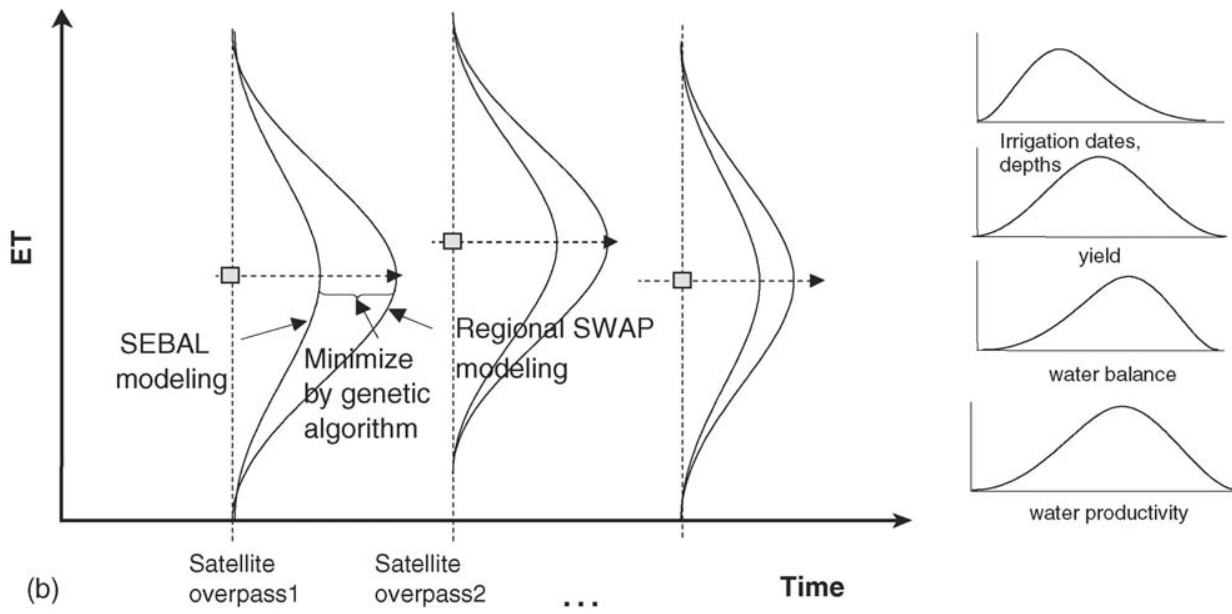

water balance

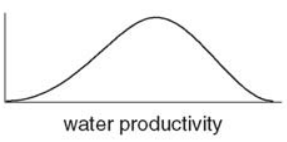

(b)

overpass 1

overpass2

Fig. 2 - (a) Modeling framework used in the study: (i) system characterization (bold dashed line enclosure), and (ii) exploring water management options (thin dashed line enclosure). (b) Schematic of the stochastic data assimilation technique where the distributions of ET calculated by SEBAL are matched with SWAP simulations using genetic algorithm.

bootstrap to resample the distributions to generate distributed input data for the regional application of SWAP to produce results that could describe the spatial and temporal behaviour of the hydrologic system given the current climatic and environmental conditions. SWAP is used to simulate the physical processes of the homogenous land unit derived by bootstrapping.

SWAP is a physically-based, field scale agro-hydrological model used to simulate the interrelationships of the soil, water, atmosphere and plant system. The model can be applied under variably saturated flows hence favorable for water management studies in irrigated agriculture. SWAP solves the 1D Richards' equation (Eq. (2.1)) to simulate the soil water movement in the soil profile, where $\theta$ is the soil water $\left(\mathrm{cm}^{3} \mathrm{~cm}^{-3}\right), h$ the pressure head $(\mathrm{cm}), \mathrm{K}$ the unsaturated hydraulic conductivity $\left(\mathrm{cm} \mathrm{d}^{-1}\right)$; $z$ the soil depth taken positive upwards $(\mathrm{cm}), C$ the water capacity $(\mathrm{d} \theta / \mathrm{dh})\left(\mathrm{cm}^{-1}\right) . S_{\mathrm{a}}$ is the sink term $\left(\mathrm{cm}^{3} \mathrm{~cm}^{-3} \mathrm{~d}^{-1}\right)$ defined in case of uniform root distribution in Eq. (2.2), where $T_{p}$ is the potential transpiration $\left(\mathrm{cm} \mathrm{d}^{-1}\right), \mathrm{z}_{\mathrm{r}}$ the rooting depth $(\mathrm{cm})$ and $\alpha_{\mathrm{w}}$ is a reduction factor as a function of $h$ and accounts for water deficit and oxygen stress (Feddes et al., 1978):

$$
\begin{aligned}
& \frac{\partial \theta}{\partial t}=C(h) \frac{\partial h}{\partial t}=\frac{\partial[K(h)(\partial h / \partial z+1)]}{\partial z}-S_{a}(h) \\
& S_{a}(h)=\alpha_{w}(h) \frac{T_{p}}{\left|z_{\mathrm{r}}\right|}
\end{aligned}
$$

The soil hydraulic functions are defined by the Mualem-Van Genuchten (MVG) equations (Eqs. (2.3) and (2.4)), where $S_{e}$ is the relative saturation $(-), \theta_{\text {res }}$ and $\theta_{\text {sat }}$ are the residual and saturated soil water contents $\left(\mathrm{cm}^{3} \mathrm{~cm}^{-3}\right), \alpha\left(\mathrm{cm}^{-1}\right), n(-), m(-)$ and $\lambda(-)$ are shape parameters of the retention and the conductivity functions, $K_{\text {sat }}$ is the saturated hydraulic conductivity $\left(\mathrm{cm} \mathrm{d}^{-1}\right) ; m=1-1 / n$. These functions describe the capacity of the soil to store, release and transmit water under different environmental and boundary conditions. The soil hydraulic parameters $\alpha, n, \theta_{\text {res }}, \theta_{\text {sat }}, K_{\text {sat }}$ and $\lambda$ are 
unique for each soil type and have to be determined for the model applications.

$\mathrm{S}_{\mathrm{e}}=\frac{\theta(h)-\theta_{\text {res }}}{\theta_{\text {sat }}-\theta_{\text {res }}}=\left[\frac{1}{1+|\alpha h|^{n}}\right]^{m}$

$\mathrm{K}(h)=K_{\mathrm{sat}} \mathrm{S}^{\lambda}\left[1-\left(1-\mathrm{S}_{\mathrm{e}}^{1 / m}\right)^{m}\right]^{2}$

SWAP is capable of accounting for several combinations of the top and bottom boundary conditions. It is equipped with numerical crop growth simulation model, e.g. WOFOST (Boogaard et al., 1998) and water management modules for crop simulation and irrigation and drainage studies. The model simulates both the fate and transport of soil water and solutes. The potential evapotranspiration (ET $\mathrm{E}_{\mathrm{p}}$ is calculated by Penman-Monteith equation, where the components, potential transpiration $\left(T_{p}\right)$ and soil evaporation $\left(E_{p}\right)$, are partitioned using leaf area index (LAI) or soil cover fraction (SC) of the homogenous land unit. As the soil dries, the model reduces $\mathrm{ET}_{\mathrm{p}}$ into $\mathrm{ET}_{\mathrm{a}}$ (actual ET), where the $\mathrm{E}_{\mathrm{p}}$ component is reduced to $E_{\mathrm{a}}$ according to some established empirical relationships or by Darcy's law applied in the soil surface, and $T_{p}$ into $T_{a}$ using a water stress reduction factor. The model has been used in various applications and has been well validated under different climatic and environmental conditions (e.g. Wesseling and Kroes, 1998; Droogers et al., 2000; Droogers and Bastiaanssen, 2002; Van Dam, 2000; Sarwar et al., 2000; Ahmad et al., 2002).

\subsubsection{Stochastic data assimilation}

We used a modified-microGA (Carroll, 1998; Ines and Droogers, 2002a) to estimate the means ( $\left.\mu^{\prime} \mathrm{s}\right)$ and standard deviations $\left(\sigma^{\prime} \mathrm{s}\right)$ of the selected stochastic variables namely, sowing dates, irrigation application criterion $\left(\mathrm{T}_{\mathrm{a}} / \mathrm{T}_{\mathrm{p}}\right)$, soil hydraulic properties (i.e. the $\alpha$ and $n$ in the MVG equations), depth to groundwater and water quality. We chose these variables as stochastic as they are believed to be the most sensitive affecting the spatial and temporal variations of ET in the study area (Droogers et al., 2001a; Droogers et al., 2001b; Ines and Droogers, 2002a; Jhorar et al., 2002). The modified-microGA uses a micro population to sample the global search space. The steps used for the stochastic parameter estimation technique are given as follows:

(1) Code the parameters (i.e. means and standard deviations of each variable) into binary sub-strings (0s and 1s) and arrange them as an array to form a chromosome.

(2) Initialize the micro-population to generate initial set of chromosomes.

(3) Evaluate each chromosome by decoding them into their decimal values (base 10) and use them as inputs for the regional SWAP modeling. Here, the probability density function of each variable in a chromosome is resampled to generate a combination of deviates that would represent a homogenous soil unit to be simulated by SWAP. The resampling is done many times to generate a distribution of ET in the system. The fitness of a chromosome is evaluated by comparing the distributions of ET simulated by SWAP and from SEBAL for the specific days of interest (Fig. 2b).

(4) Based on their fitness, the chromosomes are selected to mate (now in binary form) in the mating pool. Each selected chromosome is randomly paired a mate then
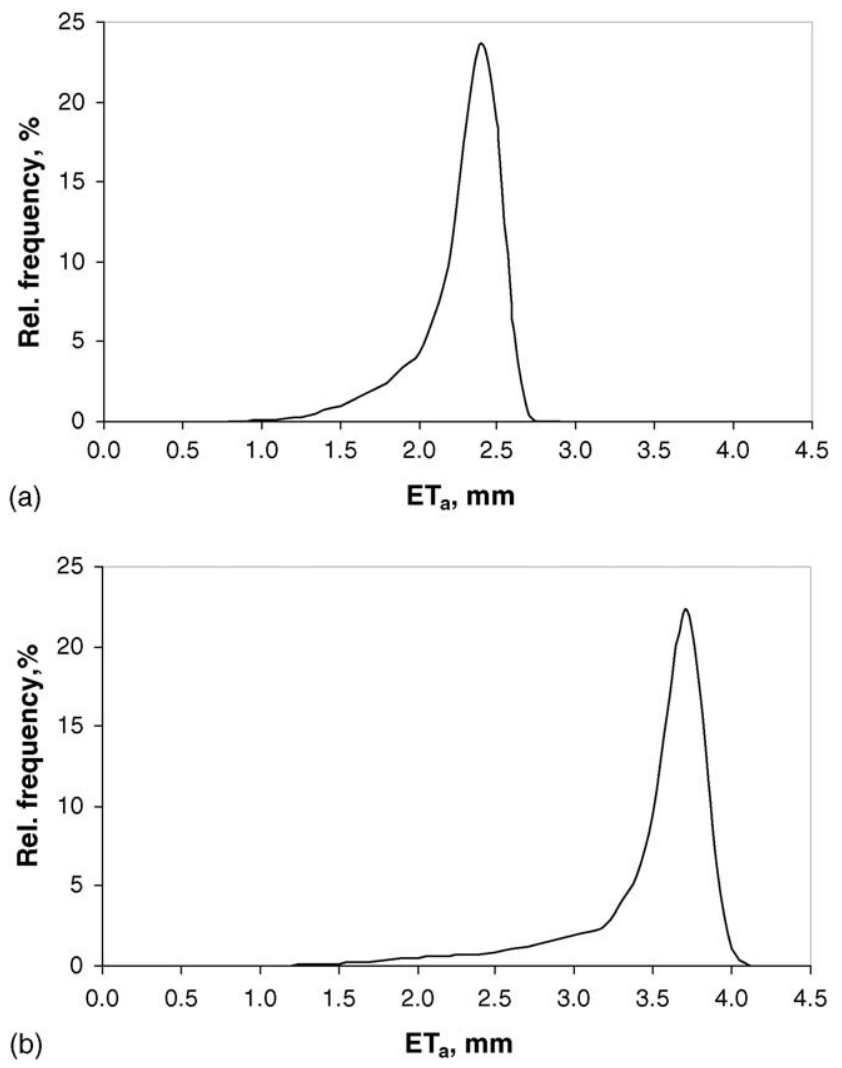

Fig. 3 - Estimated spatial ET from Landsat7 ETM+ for: (a) February 2 and (b) March 8, 2001 using SEBAL (after Ines and Droogers, 2002b).

exchange genetic information via crossover, and subject to mutation (in this case creep mutation; Carroll, 1998). In a modified-microGA the population is allowed to restart if the bits' positions in the micro-population are nearly $90 \%$ similar.

(5) Steps 3-4 are repeated to many generations until the solution is achieved. Further details on genetic algorithms can be seen in Goldberg (1989).

We applied the method to the wheat (Triticum aestivum) cropped areas in the study area during the 2000-2001 rabi season. We used two Landsat 7ETM+ images obtained in February 4 and March 8, 2001. Fig. 3a and b show the distributions of ET calculated by SEBAL for the selected images. The wheat cropped areas were delineated by truncating the skewed ET distribution to form a normal curve and the pixels under the normal curve are the only ones used in the analysis. Table 1 shows the results of the data assimilation procedure. The results are used as inputs to the water management optimization. Further details can be seen in Ines and Droogers (2002b).

\subsubsection{Water management optimization model}

2.2.3.1. Model formulation. After system characterization, we explored water management options using a simple water management optimization model described as follows. We assume the properties, $\boldsymbol{k}_{\mathrm{i}}=\left\{\boldsymbol{p}_{j=1, \cdots, m}\right\}$, of an irrigation system 
Table 1 - Genetic algorithm solution for the regional inverse problem ${ }^{\mathrm{a}}$

\begin{tabular}{lll} 
Stochastic variables & \multicolumn{1}{c}{ Mean } & \multicolumn{1}{c}{ S.D. } \\
\hline$\alpha$ & 0.0212 & 0.0252 \\
$n$ & 1.4144 & 0.0381 \\
Emergence date & November 22 & 7 days \\
Depth to groundwater & $435 \mathrm{~cm}$ & $33.5 \mathrm{~cm}$ \\
Irrigation scheduling $\left(\mathrm{T}_{\mathrm{a}} / \mathrm{T}_{\mathrm{p}}\right)$ & 0.72 & 0.28 \\
Irrigation water quality & $2.4 \mathrm{dS} \mathrm{m}^{-1}$ & $0.74 \mathrm{dS} \mathrm{m}^{-1}$ \\
\hline
\end{tabular}

Note: $T_{a}$, actual transpiration; $T_{p}$, potential transpiration

a After Ines and Droogers (2002b).

as stochastic, i.e. $p_{j}=\mathbb{N}\left(\mu_{j}, \sigma_{j}^{2}\right)$, where $i=1, \ldots, N ; j$ is a running index for system properties; $m$ the number of system properties of interest, a regional water management optimization model can be formulated as follows. Consider $N \in \mathbf{M}$, where $\mathrm{N}$ is the number of random simulation units (i.e. $k_{1}, k_{2}, \ldots, k_{N-1}$, $k_{N}$ ); and $M$ the population of simulation units in the system $(S)$, the objective function-maximizing regional yield $\left(Z_{\max }\right)$, can be defined as:

$Z_{\max }=\max _{N \in M}\left(\frac{1}{N} \sum_{i=1}^{N} Y_{i}\right)$

subject to these constraints:

a) water availability

$$
\frac{1}{N} \sum_{i=1}^{N} \operatorname{Ir}_{i}=Q_{\text {aves }}
$$

b) range of water management practices

$$
\begin{aligned}
& \mu_{1 \text { min }} \leq \mu_{1} \leq \mu_{1 \text { max }} \\
& \sigma_{1 \text { min }} \leq \sigma_{1} \leq \sigma_{1 \text { max }}
\end{aligned}
$$

c) range of crop management practices

$$
\begin{aligned}
& \mu_{2 \min } \leq \mu_{2} \leq \mu_{2 \max } \\
& \sigma_{2 \min } \leq \sigma_{2} \leq \sigma_{2 \max }
\end{aligned}
$$

we define the above variables in Eqs. (2.5) and (2.6) in functional forms as:

$$
\begin{aligned}
& \operatorname{Ir}_{i}=f\left\{\mathbb{N}\left(\mu_{1}, \sigma_{1}^{2}\right), \mathbb{N}\left(\mu_{2}, \sigma_{2}^{2}\right), \mathbb{N}\left(\mu_{3}, \sigma_{3}^{2}\right), \mathbb{N}\left(\mu_{4}, \sigma_{4}^{2}\right)\right\}_{i} \\
& Y_{i}=f\left\{\mathbb{N}\left(\mu_{1}, \sigma_{1}^{2}\right), \mathbb{N}\left(\mu_{2}, \sigma_{2}^{2}\right), \mathbb{N}\left(\mu_{5}, \sigma_{5}^{2}\right)\right\}_{i} \\
& Q_{\text {aves }}=f\left(Q_{c}, Q_{\text {gw }}\right)_{S}
\end{aligned}
$$

The definitions of the variables and parameters in Eqs. (2.5)(2.13) are given as follows. The decision variables are defined by the: (i) water management variable, represented by the irrigation scheduling criteria practiced by the farmers $\left(T_{a} / T_{p}\right)$ expressed by the parameters, $\mu_{1}$ (mean) and $\sigma_{1}$ (standard deviation); (ii) crop management variable represented by the emergence dates of the crops (a surrogate for sowing dates in SWAP) expressed by parameters, $\mu_{2}$ and $\sigma_{2}$. The seasonal irrigation (Ir) in a random simulation unit $i$ is a function of the water and crop management practices [i.e $\mu_{1}, \sigma_{1}$ and $\mu_{2}, \sigma_{2}$ ] and soil properties [i.e. $\mu_{3}$ and $\sigma_{3}$ for $\alpha ; \mu_{4}$ and $\sigma_{4}$ for $n$ ]. Yield (Y) is a function of crop and water management [i.e. $\mu_{1}, \sigma_{1}$ and $\mu_{2}$, $\sigma_{2}$ ] and water quality (i.e. $\mu_{5}, \sigma_{5}$ ). Crop yield is simulated by WOFOST (Boogaard et al., 1998), a dynamic, process-based, crop simulation model. WOFOST responds systematically to the stresses caused by the management and water quality variables considered. Definitions of the other variables are given as follows: $Q_{\text {aves }}$ is the seasonal average water available in system $S$ (boundary of $\mathbf{M}$ ) from canal and groundwater supply; $Q_{c}$ the canal water; $Q_{g w}$ the groundwater; seasonal average water available is defined as an areal-average water supply (ha $\mathrm{mm} \mathrm{ha}^{-1}$ ).

\subsection{Genetic algorithm implementation}

Take the relaxed constraints:

$L L \leq \frac{1}{N} \sum_{i=1}^{N} \operatorname{Ir}_{i} \leq U L$

where

$L L=(1-\phi) Q_{\mathrm{aveS}}$

$\mathrm{UL}=(1+\phi) \mathrm{Q}_{\mathrm{aveS}}$

Here, we used $\phi=0.05$, this value is arbitrarily chosen to give bounds to the optimal region of the system-wise, seasonal average of Ir; the narrower the non-penalized region around $\mathrm{Q}_{\text {ave, }}$, the more-unique the solutions would be. The water management optimization model was implemented in GA using the penalty approach of Goldberg (1989) (Eq. (2.16)), where fitness is a measure of the chromosome, $\mathbf{k}=\left\{\mu_{1}, \sigma_{1}, \mu_{2}, \sigma_{2}\right\}, \varphi_{\ell}$ is a penalty used to penalize a chromosome violating Eqs. (2.14) and (2.15). Limit is the bounds $[\ell=1(L L), 2(U L)]$ of the allowable range of average water use.

fitness $(\boldsymbol{k})_{\max }=\operatorname{Max}\left\{\frac{1}{N} \sum_{i=1}^{N} Y_{i}-\sum_{\ell=1}^{2} \varphi_{\ell}\left(\frac{1}{N} \sum_{i=1}^{N} \operatorname{Ir}_{i}-\text { Limit }_{\ell}\right)^{2}\right\}$

In the application, the means and standard deviations of the water quality variable and soil properties are assumed to be initially known and taken from Table 1 . Since the groundwater table is relatively deep, we assumed the soil (500 cm depth) to be free-draining (the bottom boundary condition in under unit hydraulic gradient). This condition, however, is not always wise to impose because we exclude entirely the interaction between the vadose zone and the groundwater. The soil system was assumed to be relatively dry during the start of simulations. It was assumed that the soil has an average initial salinity level of $4 \mathrm{dS} \mathrm{m}^{-1}$. Several water management scenarios were considered to observe the solutions of the water management optimization model, when water is severely limiting ( $\left.Q_{\text {ave }} \sim 200 \mathrm{~mm}\right)$, and when it is non-limiting ( $Q_{\text {ave }} \sim 600 \mathrm{~mm}$ ). The procedure used to solve the water optimization problem is similar to steps 1-5 in Section 2.2.2, only, the fitness function used is given by Eq. (2.16), and the chromosome is given by $k$. 


\subsection{Water productivity}

We evaluated three levels of water productivity using the optimal combinations of management practices- $\mathrm{PW}_{\text {Irrigated, }}$ $\mathrm{PW}_{\text {Depleted }}$ and $\mathrm{PW}_{\text {Process }}($ Eqs. (2.17)-(2.19)) (Molden, 1997), where PW stands for water productivity $\left(\mathrm{kg} \mathrm{m}^{-3}\right), \mathrm{ET}_{\mathrm{a}}$ for actual evapotranspiration $(\mathrm{mm}), \mathrm{T}_{\mathrm{a}}$ for actual transpiration $(\mathrm{mm}), \mathrm{N}$ is the number of random homogeneous units, $\mathrm{C}$ a constant equal to 0.1 ha $\mathrm{mm} \mathrm{m}^{-3}$ and $i$ an index for homogenous land unit.

$\mathrm{PW}_{\text {Irrigated }}=\mathrm{C} \frac{1}{\mathrm{~N}} \sum_{i=1}^{N}\left(\frac{Y}{\mathrm{Ir}}\right)_{i}, \quad$ if $\mathrm{Ir}_{i}=0 ; \mathrm{PW}_{\text {Irrigated }}=0$

$\mathrm{PW}_{\text {Depleted }}=\mathrm{C} \frac{1}{\mathrm{~N}} \sum_{\mathrm{i}=1}^{\mathrm{N}}\left(\frac{\mathrm{Y}}{\mathrm{ET}_{\mathrm{a}}}\right)_{i}$

PW $_{\text {Process }}=C \frac{1}{N} \sum_{i=1}^{N}\left(\frac{Y}{T_{a}}\right)_{i}$

$\mathrm{PW}_{\text {Irrigated }}$ defines the efficiency of the total irrigation to produce an economic yield. $\mathrm{PW}_{\text {Depleted }}$ defines the yield conversion per unit of ET loss. PW Process defines a higher order of water use efficiency, where the actual amount of water transpired is related to yield.

\section{Results and discussions}

\subsection{Best management options}

Fig. $4 \mathrm{a}$ and $\mathrm{b}$ show the solution of GA to the water management optimization model when the average water available is $\sim 200 \mathrm{~mm}$. GA is capable of converging to the most probable combination of the crop and water management practices to achieve the best possible regional yield while not violating the imposed average water use limits. Similar trends are observed with the other water management scenarios (Table 2). The limited number of generations was deliberately used to minimize the computational time because every chromosome $(k)$ in a generation is resampled 250 times to capture the spatial behaviour of the system (Table 2). This option was wise because with the solute transport module invoked together with normal SWAP routines require significant amount of time to complete simulations for one cropping season. The problem of computational time would not be a big hindrance in the near future. Cieniawski et al. (1995) and Cai et al. (2001) observed that GA can arrive at the global or near global solution between 10 and 20 generations even with complex water management optimization models. We tried extending the number of generations to solve our water management scenario ( $200 \mathrm{~mm}$ ) and found approximately similar results after the 10th generation (Fig. 4b).

The results in Table 2 show that when water is very limited, equitable water distribution can increase the overall system performance. This means that the limited water supply should be spread equitably among the stakeholders. This finding is analogous to the principle of warabandi (Berkoff and Huppert, 1987; Bandaragoda, 1998). In this case, $\sim 68 \%$ of the farmers can allow water stress
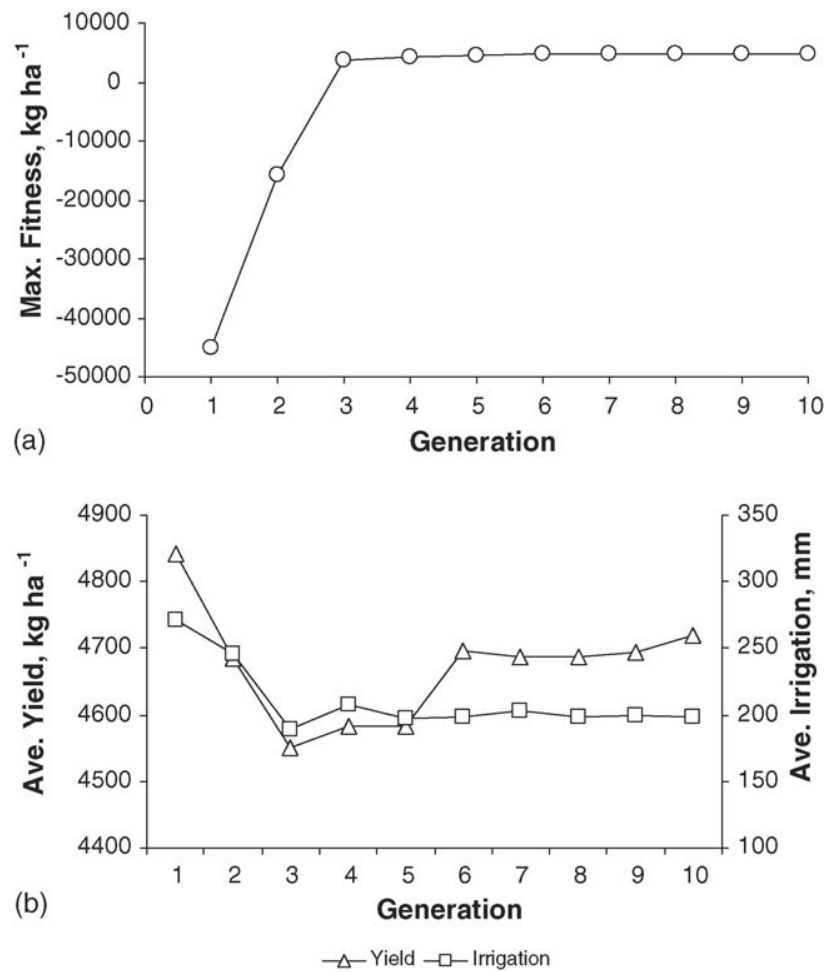

Fig. 4 - Solution of the water management optimization model when average seasonal water available in the system, $Q_{\text {aves }}=200 \mathrm{~mm}$ : (a) evolution of maximum fitness and (b) average yield and irrigation as a function of number of generations.

$\left(1-T_{a} / T_{p}\right)$ levels between 29 and $35 \%$ to their crops before irrigation. To achieve this, a wider distribution of sowing dates is required and they should be done earlier in the growing season. During times when water is non-limiting

Table 2 - Best management options derived by genetic algorithm ${ }^{\mathrm{a}}$

\begin{tabular}{|c|c|c|c|c|}
\hline \multirow{2}{*}{$\begin{array}{l}\text { Average } \\
\text { water } \\
\text { supply (mm) }\end{array}$} & \multicolumn{2}{|c|}{$\begin{array}{c}\text { Water } \\
\text { management }^{\mathrm{b}}\end{array}$} & \multicolumn{2}{|c|}{$\begin{array}{c}\text { Crop } \\
\text { management }^{c}\end{array}$} \\
\hline & Mean & S.D. & Mean & S.D. \\
\hline 200 & 0.68 & 0.03 & November 11 & 12 \\
\hline 300 & 0.73 & 0.28 & November 11 & 20 \\
\hline 400 & 0.88 & 0.13 & November 26 & 2 \\
\hline 500 & 0.93 & 0.06 & November 18 & 10 \\
\hline 600 & 0.94 & 0.06 & November 18 & 19 \\
\hline
\end{tabular}

Note: A $91 \mathrm{~mm}$ rainfall was recorded during the cropping season.

a Genetic algorithm parameters used in the water management optimization are as follows: population size, 10; number of generation, 10; probability of crossover, 0.50 ; probability of creep mutation, 0.10; length of string, 40 bits; penalty coefficient, 10 for any violation; and the rate of resampling in extended SWAP is 250.

${ }^{b}$ Irrigation scheduling criterion, $T_{a} / T_{p}$ (a $100 \mathrm{~mm}$ of water is applied when this criterion is met).

Sowing dates, represented here by the emergence dates; standard deviation (S.D.) is in number of days. 
( $600 \mathrm{~mm}$ ) high equity of water distribution will result to better benefits for the farmers. It is obvious, however, that the farmers have to share the convenience of the abundant water supply as they have also higher degrees of freedom in their planting activities.

The results also show that when water supply is just enough $(\sim 400 \mathrm{~mm})$, a relative degree of inequity in water distribution can be tolerated. The farmers should sow their seeds at later dates and in a synchronized manner; from November 24 to 28 about $68 \%$ of the area should be grown to wheat crops already. This is difficult to achieve without farm mechanization. It is likely, however, that this result is sub-optimal as it is very different from the trends in Table 2.
For the real world case scenario $(\sim 300 \mathrm{~mm})$ the solution shows a good agreement between the optimal water management practice with that of the existing one (Tables 1 and 2), only, the optimal sowing date should be done earlier with wider distribution in the growing season. Early sowing dates may not be always possible since the previous crop could be still standing in the field. The reason is unclear why equity in water distribution should not be of high priority in this case. A possible explanation could be, the wider distribution of sowing dates may give some farmers greater degrees of freedom to use more water than the others. However, this may have resulted to the collective improvement of the expected regional yield of wheat, as this is only the objective of the water management optimization model.
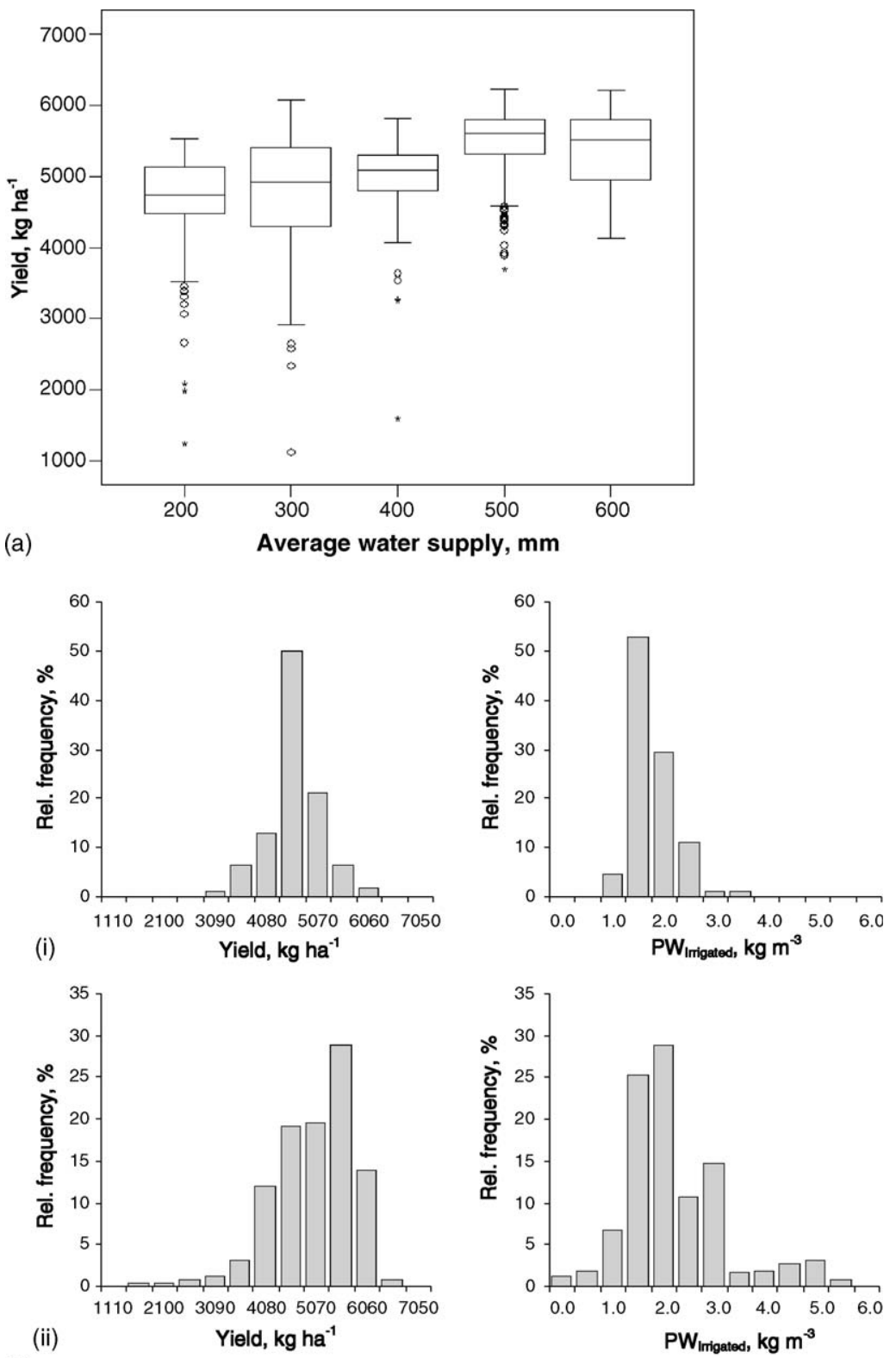

(b)

Fig. 5 - (a) Crop yields at different levels of water availability generated from the best management practices. (b)

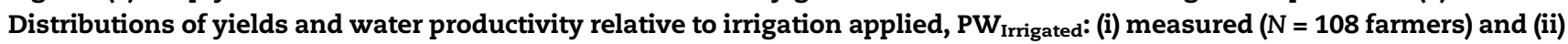
with optimization ( $\mathrm{N}=250$ realizations) for 2000-2001 rabi (dry) season. (Legend: $(\bigcirc)$ outliers, $(*)$ extreme values). 
Note that these analyses were based on the assumption that average water supply comes from surface and groundwater. Debates on the extent of groundwater contribution to surface water for surface irrigation can be addressed by the results in Table 1 as follows: the average salinity level of the irrigation water according to Table 1 is $2.4 \mathrm{dS} \mathrm{m}^{-1}$, since we know that the salinity level of canal water is less than 0.5 and of groundwater about $4 \mathrm{dS} \mathrm{m}^{-1}$, the ratio of groundwater to canal water is approximately $60-40$, near to the estimates of Tyagi et al. (2005) for 2000-2001 rabi season in Bata minor. Exploring further this approach to estimate groundwater use in surface irrigation is certainly promising.

\subsection{Crop yields and water productivity}

Fig. 5a shows the expected regional yields with the different water management scenarios. Apparently, there are outliers at the lower ends of the distributions - these are probably the simulated yields with very little amount of irrigation combined with high levels of salinity. Considering the quartiles $\left(q_{1}, q_{3}\right)$ above the outliers, with very limited water supply, about $50 \%$ of the farmers could still expect yields between 4500 and $5200 \mathrm{~kg} \mathrm{ha}^{-1}$. The earlier date of sowing could have contributed to the yield level due to the effect of higher accumulated solar radiation. For the actual case, the expected regional yield is $\sim 4800 \mathrm{~kg} \mathrm{ha}^{-1}$ (slightly below the median), which is about $8.5 \%$ higher than the observed average yield ( $4400 \mathrm{~kg} \mathrm{ha}^{-1}$, Hussain et al., 2003). From our cropped area delineation procedure in Section 2.2.2, about $90 \%$ of the total command area of Bata minor was planted to wheat during 2000-2001 rabi season, very near to the data collected by Tyagi et al. (2005) from 108 farmers. Translating the possible improvement in the volume of produce would be on the order of $1.4 \mathrm{Mt}$ of wheat grains. Fig. $5 \mathrm{~b}$ shows the distributions of yield and water productivity with current practices and with optimization. Integrated stochastic modeling seems to allow more opportunities for sampling the system giving more chance to explore the system better provided that all the models used are properly calibrated. Obviously, with higher water supply increases the produc-

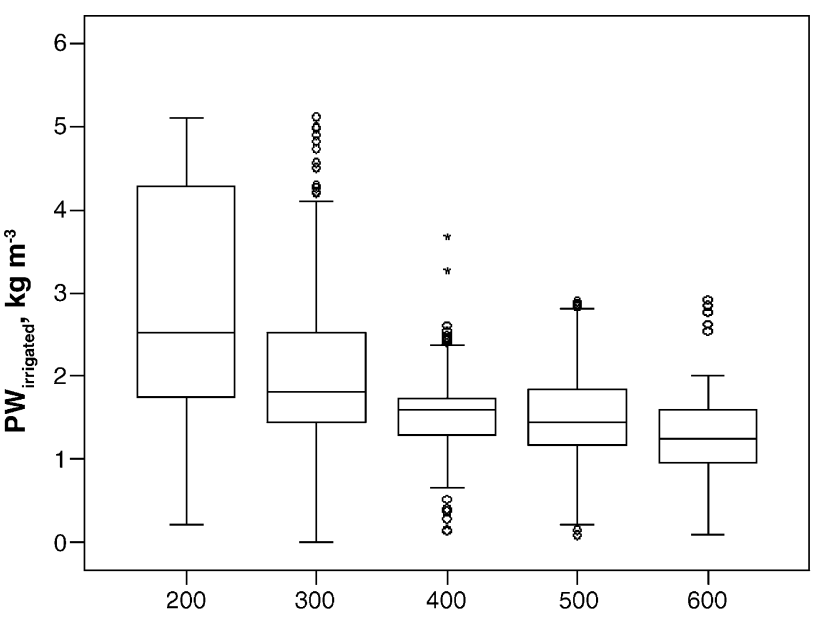

(a)

Average water supply, $\mathrm{mm}$
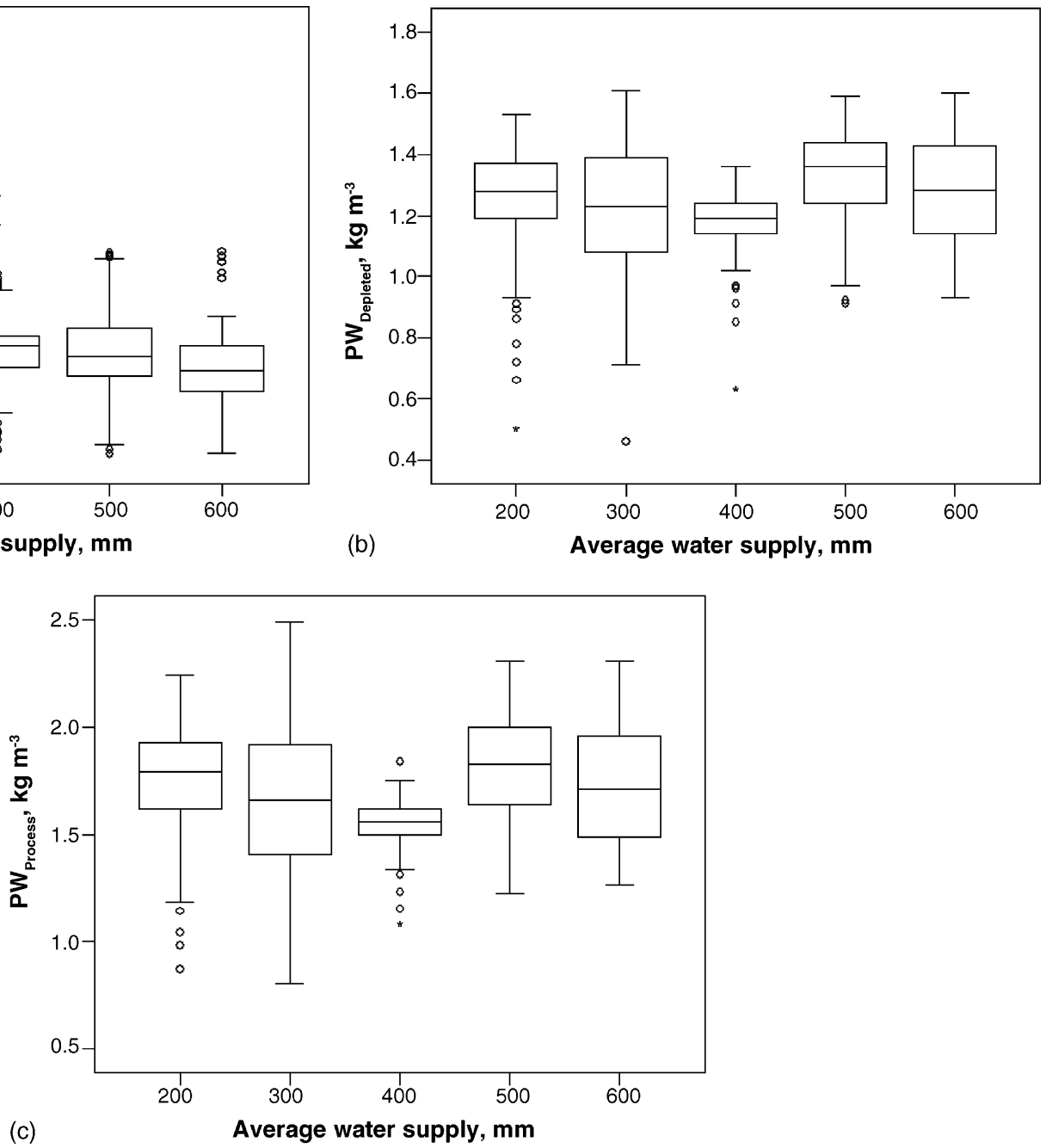

Fig. 6 - (a) Water productivity relative to: irrigation applied, $\mathrm{PW}_{\text {Irrigated, }}$ at different levels of water availability generated from the best management practices; (b) evapotranspiration, $\mathrm{PW}_{\text {Depleted, }}$ at different levels of water availability generated from the best management practices; and (c) crop transpiration, $\mathrm{PW}_{\text {Process, }}$ at different levels of water availability generated from the best management practices. (Legend: $(\bigcirc)$ outliers, $\left({ }^{*}\right)$ extreme values). 
tivity of wheat as there is enough water to meet the crop water and leaching requirements (Fig. 5a). But as the law of diminishing return holds, there is an optimum point where the marginal benefit justifies any further increase in water inputs-beyond this point, water can be saved. The decrease in yield could be attributed to the excess water, which causes oxygen stress to the crops. SWAP applies the product of daily stresses (water/oxygen and salt) to reduce the actual biomass production in a day. The sink of wheat ET during the rabi (dry) season caused by reduced irrigation applications will be replenished by rainfall during the monsoon period. Some of the salts that would possibly accrue in the surface will be washed out by surface runoff into the surface drainage system (Section 2.1). In future modeling, however, considering the salinity built-up in the soil surface as a constraint in the optimization problem would provide a broader consideration of the existing problems in the study area.

Fig. $6 a-c$ show the water productivities calculated from the derived optimal management strategies. Water productivities vary with levels of water supply. An intrinsic property of $\mathrm{PW}_{\text {Irrigated }}$ is that it decreases asymptotically with increasing water supply (Ines, 2002). No linear relationship either is observed on the amount of water applied and $\mathrm{PW}_{\text {Depleted }}$, and $\mathrm{PW}_{\text {Process. }}$ This is likely to be explained by the limiting factors that dominate crop growth when water applied is very limited or in abundant supply, which are salinity, water and oxygen stress. Due to the effect of antecedent soil moisture and rainfall in the growing season (here, $91 \mathrm{~mm}$ ), crops still could produce some yields when water is very limited. Relatively higher yield with low ET would produce high $\mathrm{PW}_{\text {Depleted. Note here that wheat is }}$ moderately tolerant to salts. As the depth of water applied increases, ET also increases, and the yield tends to increase as this also reduces the levels of water and salinity stress experienced by the crops. But at some point where the atmospheric demand is fully met, ET does not increase any longer; the excess water would be loss through surface runoff or by percolation, thus leaching the salts. As mentioned above, too much water would induce oxygen stress to the crops, reducing crop yields under such a condition. Note also that we considered the soil as spatially variable in the analysis, hence, it does not have similar hydraulic behavior in every homogenous land unit. A recent survey of Zwart and Bastiaanssen (2004) shows that the measured water productivities ( $\left.\mathrm{PW}_{\text {Depleted }}\right)$ of wheat ranged from 0.6 to $1.7 \mathrm{~kg} \mathrm{~m}^{-3}$ which coincides with our results (Fig. $6 \mathrm{~b}$ for $300 \mathrm{~mm}$ scenario). The observed average $\mathrm{PW}_{\text {Irrigated }}$ is $1.5 \mathrm{~kg} \mathrm{~m}^{-3}$, our solution suggests an optimal value of $\mathrm{PW}_{\text {Irrigated }} \sim 1.8 \mathrm{~kg} \mathrm{~m}^{-3}$ (Fig. 6a) and average $\mathrm{PW}_{\text {Process }}$ of $\sim 1.6 \mathrm{~kg} \mathrm{~m}^{-3}$ (Fig. 6c).

\subsection{Implications to water management}

Equitable water distribution can improve the performance of the irrigation system. When equity is high, fairness to farmers' share to what is available in the system is highly regarded. In our perspective, it appears that a rotational water delivery scheme at the minor (lateral) level could improve further the performance of a warabandi system. From field observations, the only portion of the canal hierarchy where flexibility could happen under this rigid water delivery scheme is at the minor canal. The periods when water is allowed to flow in the canal are windows of opportunity to rotate the water deliveries to the field canals (Section 2.1). There is a limitation of this observation. The minor canals are not designed to handle such a rotational water delivery. An option is to make a zonation along minor canals, e.g. head, middle and tail sections (meaning group of watercourses), where rotation can be done in an equitable manner every time water is available. Slight structural amendment could be done in this case like installing water level control structures at each zone boundary. The offtake structure of the minor could control the flow of water in the canal. Note, however, that every decision made at the lower level of the canal hierarchy could impact to the decisions upstream because of the possible change in the flow regime. Further study is needed to evaluate this hypothesis, perhaps using a canal water management model coupled with an agro-hydrological model.

A need to delineate the impact of groundwater in the solution is necessary to make better recommendations for the real situation in the field. As mentioned earlier, making use of the different salinity levels of groundwater and canal water in combination with inverse modeling allows estimating this groundwater contribution (Gieske et al., 2000; Ahmad et al., 2002).

\section{Summary and conclusions}

The purpose of this paper is to explore water management options in irrigated agriculture by using a combined RSsimulation modeling and genetic algorithm optimization. We used remote sensing to characterize our regional system via a stochastic data assimilation approach, and then the derived data were used as inputs to our water management optimization model. Although the analyses were limited to the conditions imposed in the water management optimization model, some basic but useful findings have been drawn on how to make use to the best possible way the limited water supply available in an irrigation system.

Results showed that regional crop productivity can be improved by considering water and crop management practices as one, not as independent entities under limited water condition. Adjusting sowing dates and their distributions in the irrigated area were found to impact positively the regional yield. This management option could complement the practice of deficit irrigation. On the average, the farmers could allow their crops to experience water stress of about $27 \%$ before irrigation, with the current conditions in the study area. This could result to an increase of about $8.5 \%$ in the expected regional wheat yield and regional water productivity ( $\mathrm{PW}_{\text {Pro- }}$ cess) of $\sim 1.6 \mathrm{~kg} \mathrm{~m}^{-3}$.

When water supply is very limited, high equity in water distribution could result to a better performance of the irrigation system, and this should be also complemented by an earlier date of sowing in the growing season with wider distribution. This is also true when water is non-limited but the farmers have higher degrees of freedom in their planting activities. There is an optimum point where the benefit would 
justify additional use of water for irrigation, beyond this point, water should be saved.

In a more proactive mode, if seasonal climate forecast is available, the approach can be applied to explore water management decisions before the wheat growing season (Hansen and Ines, 2005). In future modeling, we recommend considering the salinity built-up in the soil surface as a constraint in the optimization problem. This would provide a broader consideration of the existing problems in the study area.

\section{Acknowledgement}

The authors wish to acknowledge the financial support given by the International Water Management Institute (IWMI) of Colombo, Sri Lanka for this research. Dr. N.K. Tyagi, Director of the Central Soil Salinity Research Institute (CSSRI) of Karnal, Haryana, India is appreciated for all the help he has given during the conduct of the field study.

\section{R E F E R E N C E S}

Ahmad, M., Bastiaanssen, W.G.M., Feddes, R.A., 2002. Sustainable use of groundwater for irrigation: a numerical analysis of the subsoil water fluxes. Irrig. Drain. 51, 227-241.

Bandaragoda, D.J., 1998. Design and practice of water allocation rules: lessons from warabandi in Pakistan's Punjab. Research Report 17. International Irrigation Management Institute, Colombo, Sri Lanka.

Bastiaanssen, W.G.M., Allen, R.G., Droogers, P., D’Urso, G., Steduto, P., 2004. Inserting man's irrigation and drainage wisdom into soil water flow models and bringing it back out: how far have we progressed? In: Feddes, R.A., de Rooij, G.H., van Dam, J.C., Bogers, R.J. (Eds.), Unsaturated-Zone Modeling: Progress, Challenges and Applications. Wageningen University, Wageningen, The Netherlands, pp. 263-299.

Bastiaanssen, W.G.M., Menenti, M., Feddes, R.A., Holtslag, A.A.M., 1998. A remote sensing surface energy balance algorithm for land (SEBAL). 1. Formulation. J. Hydrol. 212213, 198-212.

Berkoff, J., Huppert, W., 1987. Matching crop water requirements in large systems with a variable water supply: experiments in India. ODI-IIMI Irrigation Management Network Paper 87/3d. Overseas Development Institute, London.

Bos, M.G., 1997. Performance indicators for irrigation and drainage. In: Irrigation and Drainage Systems, vol. 11, No. 2. Kluwer, Dordrecht, pp. 119-137.

Bos, M.G., Nugteren, J., 1990. On Irrigation Efficiencies, fourth ed. (first ed., 1974). ILRI Publication 19. International Institute for Land Reclamation and Improvement, Wageningen, pp. 141.

Boogaard, H.L., Van Diepen, C.A., Rötter R.P., Cabrera, J.M.C.A., Van Laar, H.H., 1998. User's Guide for the WOFOST 7.1 Crop Growth Simulation Model and WOFOST Control Center 1.5. Technical Document 52. DLO-Winand Staring Centre, Wageningen, pp. 144.

Boumans, J.H., Van Hoorn, J.W., Kruseman, G.P., Tanwar, B.S., 1988. Water table control, reuse and disposal of drainage water in Haryana. Agric. Water Manage. 14, 537-545.
Cai, X., McKinney, D.C., Lasdon, L.S., 2001. Solving nonlinear water management models using a combined genetic algorithm and linear programming approach. Adv. Water Resour. 24, 667-676.

Carroll, D.L., 1998. GA Fortran Driver Version 1.7, http:// www.cuaerospace.com/carroll/ga.html.

Cieniawski, S.E., Eheart, J.W., Ranjithan, S., 1995. Using genetic algorithms to solve a multiobjective groundwater monitoring problem. Water Resour. Res. 31, 399-409.

Droogers, P., Bastiaanssen, W.G.M., 2002. Irrigation performance using hydrological and remote sensing modeling. J. Irrig. Drain. Eng. 128, 11-18.

Droogers, P., Bastiaanssen, W.G.M., Beyazgül, M., Kayam, Y., Kite, G.W., Murray-Rust, H., 2000. Distributed agrohydrological modeling of an irrigation system in Western Turkey. Agric. Water Manage. 43, 183-202.

Droogers, P., Kite, G., 1999. Water productivity from integrated basin modeling. Irrig. Drain. Syst. 13, 275-290.

Droogers, P., Salemi, H.R., Manampoush, A.R., 2001a. Exploring basin-scale salinity problems using a simplified water accounting model: the example of Zayandeh Rud basin, Iran. Irrig. Drain. 50, 335-348.

Droogers, P., Torabi, M., Pazira, E., 2001b. Field-scale modeling to explore salinity problems in irrigated agriculture. Irrig. Drain. 50, 77-90.

Feddes, R.A., Kowalik, P.J., Zarandy, H., 1978. Simulation of field water use and crop yield. In: Simulation Monographs, Pudoc, Wageningen, The Netherlands.

Gieske, A., Miranzadeh, M., Mamanpoush, A.R., 2000. Groundwater Chemistry of the Lenjanat District, Esfahan Province, Iran. IAERI-IWMI Research Reports 4.

Goldberg, D.E., 1989. Genetic Algorithms in Search and Optimization and Machine Learning. Addison-Wesley Publ. Co. Inc., USA.

Hansen, J.W., Ines, A.V.M., 2005. Stochastic disaggregation of monthly rainfall data for crop simulation studies. Agric. For. Meteorol. 131, 233-246.

Hopmans, J.W., 1988. Treatment of spatially variable groundwater levels in one-dimensional stochastic unsaturated water-flow modeling. Agric. Water Manage. 15, 19-36.

Hopmans, J.W., Stricker, J.N.M., 1989. Stochastic analysis for soil water regime in a watershed. J. Hydrol. 105, 57-84.

Hussain, I., Sakthivadivel, R., Amarasinghe, U., Mudasser, M., Molden, D., 2003. Land and water productivity of wheat in the western Indo-Gangetic plains of India and Pakistan: a comparative analysis. Research Report 65. International Water Management Institute, Colombo, Sri Lanka, pp. 50.

Ines, A.V.M., 2002. Improved crop production integrating GIS and genetic algorithms. Doctoral Thesis. Asian Institute of Technology (AIT), Bangkok, Thailand, pp. 236.

Ines, A.V.M., Gupta, A.D., Loof, R., 2002. Application of GIS and crop growth models in estimating water productivity. Agric. Water Manage. 54, 205-225.

Ines, A.V.M., Droogers, P., 2002a. Inverse modelling in estimating soil hydraulic functions: A genetic algorithm approach. Hydrol. Earth Syst. Sci. 6, 49-65.

Ines, A.V.M., Droogers, P., 2002b. Inverse modeling to quantify irrigation system characteristics and operational management. Irrig. Drain. Syst. 16, 233-252.

Jesus, C.M., Marino, M.A., Holzapfel, E.A., 1987. Planning model of irrigation district. J. Irrig. Drain. Eng. ASCE. 113, 549-563.

Jhorar, R.K., Bastiaanssen, W.G.M., Feddes, R.A., Van Dam, J.C., 2002. Inversely estimating soil hydraulic functions using evapotranspiration fluxes. J. Hydrol. 258, 198-213.

Lakshminarayana, V., Rajagopalan, S.P., 1977. Optimal cropping pattern for basin India. J. Irrig. Drain. Eng. Div. ASCE (IRI). 103, 53-71. 
Molden, D., 1997. Accounting for water use and productivity. SWIM Paper. International Irrigation Management Institute, Colombo, Sri Lanka, vol. 1, pp. 16.

Mostesinos, P., Camacho, E., Alvarez, S., 2001. Seasonal furrow irrigation model with Genetic Algorithms (OPTIMEC). Agric. Water Manage. 52, 1-16.

Paudyal, G.N., Gupta, A.D., 1990. Irrigation planning by multilevel optimization. J. Irrig. Drain. Eng. 116, 273-291.

Raman, H., Mohan, S., Rangacharya, N.C.V., 1992. Decision support for crop planning during droughts. J. Irrig. Drain. Eng. 118, 229-241.

Sakthivadivel, R. Thiruvengadachari, A., Bastianssen, W.G.M., Molden, D., 1999. Performance evaluation of the Bhakra Irrigation System, India, using remote sensing and GIS techniques. Research Report 28. IWMI, Sri Lanka, pp. 22.

Sarwar, A., Bastiaanssen, W.G.M., Boers, M.Th., Van Dam, J.C., 2000. Evaluating drainage design parameters for the fourth drainage project Pakistan by using SWAP model. Part I. Calibration. Irrig. Drain. Syst. 14, 257-280.

Seckler, D., 1996. The new era of water resources management: from 'dry' to 'wet' water savings. Research Report 1. International Water Management Institute, Colombo, Sri Lanka, pp. 17.

Seckler, D., Amarasinghe, U., Molden, D., de Silva, R., Barker, R., 1998. World water demand and supply, 1990 to 2025 : scenarios and issues. Research Report 19. International Water Management Institute, Colombo, Sri Lanka, pp. 40.
Seckler, D., Barker, R., Amarasinghe, R., 1999. Water scarcity in the twenty-first century. Water Resour. Dev. 15, 29-42.

Singh, R., Singh, J., 1997. Irrigation planning in wheat (Triticum aestivum) under deep water table conditions through simulation modelling. Agric. Water Manage. 33, 19-29.

Tyagi, N.K., Agrawal, A., Sakthivadivel, Ambast, S.K., 2005. Water management decisions on small farms under scarce canal water supply: a case study from NW India. Agric. Water Manage. 77, 180-195.

Van Dam, J.C., 2000. Field-scale water flow and solute transport. SWAP model concepts, parameter estimation and case studies. Doctoral Thesis. Wageningen University, The Netherlands.

Van Dam, J.C., Huygen, J., Wesseling, J.G., Feddes, R.A., Kabat, P., Van Waslum, P.E.V., Groenendjik, P., Van Diepen, C.A., 1997. Theory of SWAP version 2.0: simulation of water flow and plant growth in the soil-water-atmosphere-plant environment. Technical Document 45. Wageningen Agricultural University and DLO Winand Staring Centre, The Netherlands.

Wesseling, J.G., Kroes, J.G., 1998. A global sensitivity analysis of the model SWAP. Report 160. DLO Winand Staring Centre, Wageningen, The Netherlands.

Zwart, S.J., Bastiaanssen, W.G.M., 2004. Review of measured crop water productivity values for irrigated wheat, rice, cotton and maize. Agric. Water Manage. 69, 115-133. 